\title{
Integrative Network-Based Analysis Reveals Gene Networks and Novel Drug Repositioning Candidates for Alzheimer Disease
}

Zachary F. Gerring, PhD, Eric R. Gamazon, PhD, Anthony White, PhD, and Eske M. Derks, PhD

Neurol Genet 2021;7:e622. doi:10.1212/NXG.0000000000000622

\section{Abstract}

\section{Background and Objectives}

To integrate genome-wide association study data with tissue-specific gene expression information to identify coexpression networks, biological pathways, and drug repositioning candidates for Alzheimer disease.

\section{Methods}

We integrated genome-wide association summary statistics for Alzheimer disease with tissuespecific gene coexpression networks from brain tissue samples in the Genotype-Tissue Expression study. We identified gene coexpression networks enriched with genetic signals for Alzheimer disease and characterized the associated networks using biological pathway analysis. The disease-implicated modules were subsequently used as a molecular substrate for a computational drug repositioning analysis, in which we (1) imputed genetically regulated gene expression within Alzheimer disease implicated modules; (2) integrated the imputed gene expression levels with drug-gene signatures from the connectivity map to identify compounds that normalize dysregulated gene expression underlying Alzheimer disease; and (3) prioritized drug compounds and mechanisms of action based on the extent to which they normalize dysregulated expression signatures.

\section{Results}

Genetic factors for Alzheimer disease are enriched in brain gene coexpression networks involved in the immune response. Computational drug repositioning analyses of expression changes within the disease-associated networks retrieved known Alzheimer disease drugs (e.g., memantine) as well as biologically meaningful drug categories (e.g., glutamate receptor antagonists).

\section{Discussion}

Our results improve the biological interpretation of genetic data for Alzheimer disease and provide a list of potential antidementia drug repositioning candidates for which the efficacy should be investigated in functional validation studies.

\author{
Correspondence \\ Dr. Gerring \\ zachary.gerring@ \\ qimrberghofer.edu.au
}




\section{Glossary}

$\mathbf{C M a p}=$ Connectivity Map; $\mathbf{e Q T L}=$ expression quantitative trait loci; $\mathbf{G T E x}=$ Genotype-Tissue Expression; $\mathbf{G W A S}=$ genomewide association study; LD = linkage disequilibrium; $\mathbf{M O A}=$ mechanism of action; NSAID = nonsteroidal anti-inflammatory drug; RPKM = Reads Per Kilobase of transcript, per Million mapped reads; SNP = single nucleotide polymorphism; UKBB = UK Biobank; WGCNA = weighted gene coexpression network analysis.

Alzheimer disease is a common neurodegenerative disorder, characterized in its early stages by mild memory loss and progressing to severe impairment of broad executive and cognitive functions. The most common form of Alzheimer disease (late-onset Alzheimer disease) typically affects individuals older than 65 years and has an oligogenic architecture, with 1 major (APOE) and around 100 smaller genetic risk factors. ${ }^{1}$ A recent genome-wide association study (GWAS) meta-analysis of 71,880 Alzheimer cases and proxy cases and 383,378 controls identified 20 disease-associated loci. ${ }^{2}$ Detailed functional studies showed that these loci harbor common (minor allele frequency $>0.01$ ) single nucleotide polymorphisms (SNPs) that regulate the activity of genes in immune-related peripheral tissues (whole blood, liver, and spleen), as well as microglial cells-the primary immune cells of the brain. Biological pathway analysis of the implicated genes shows enrichment of dysfunctional lipoprotein clearance, ${ }^{3}$ highlighting a potential link between dysfunctional lipid metabolism and immune responses in the brain. ${ }^{4}$

The integration of these genetic data with large-scale drugresponse databases provides an avenue to identify existing drugs that may alleviate the signs and symptoms of Alzheimer disease. This approach to drug discovery, known as drug repositioning, often circumvents expensive and time-consuming phase I and phase II clinical trials and may double the success rate in drug approval. ${ }^{5}$ We therefore aimed to develop an analytical pipeline to integrate genetic risk factors with drug-response data to identify novel compounds for the treatment of Alzheimer disease.

Genetic risk factors for Alzheimer disease may converge on highly correlated groups of genes that interact with one another to alter the activity of multiple biological pathways and cellular processes in a disease relevant tissue. ${ }^{6}$ Gene expression is an intermediate molecular phenotype that is directly modified by DNA sequence variation (expression quantitative trait loci [eQTLs]), epigenetic marks such as DNA methylation, and the environment, as well as the expression of other genes. ${ }^{7}$ Gene expression analyses of postmortem brain tissue have identified distinct cell types and biological pathways underlying Alzheimer pathogenesis. ${ }^{8,9}$ These studies are largely based on tests of association with individual genes or groups of curated genes with a common biological function. An alternative, agnostic approach is to model gene interactions using gene coexpression analysis, which takes the correlation between every gene pair expressed in a particular (tissue) sample to generate a molecular substrate for association testing with a disease state. ${ }^{10}$ We recently built gene coexpression networks using expression data from 14 human tissues (13 from brain) obtained from healthy donors from the Genotype-Tissue Expression (GTEx) study. ${ }^{11}$ We used these data to test for the enrichment of GWAS signals within gene coexpression modules (or groups of highly correlated genes), under the biologically relevant assumption that connectivity among genes may be leveraged to identify genes not directly implicated in disease. The use of gene expression data from healthy participants, rather than diseased cases, to build coexpression networks has a number of advantages. First, it removes the effect of ascertainment bias when collecting case and control samples, where common factors (such as medication use) underlie both the exposure of interest and the disease. ${ }^{12,13}$ Second, it mitigates the effect of reverse causation, where the disease process leads to changes in gene expression rather than the other way around. Third, for many brain-related diseases, including Alzheimer disease, the disease process is likely to start early, before the manifestation of symptoms for case ascertainment. Successful interventions are required before irreversible neuronal dysfunction and loss have occurred. Finally, expression data from nondiseased individuals are easier to collect and uniformly process in the numbers required to characterize and model complex molecular interactions. These advantages ensure the construction of a robust molecular substrate for the subsequent integration of disease associations from independent samples.

Recent studies exploring the role of gene coexpression networks have been performed using postmortem brain tissues of patients with Alzheimer disease and non-Alzheimer controls and recapitulate a role of immune and microglial biological pathways identified in GWASs. ${ }^{14}$ Groups of highly connected (i.e., correlated) immune-related genes contain central regulators (or hub genes) that are highly correlated with their neighboring genes and whose expression changes with cognitive impairment in Alzheimer disease. ${ }^{14}$ More recent integrated approaches that incorporate knowledge of network coexpression with other genomic elements (such as epigenetic modifications) identified gene targets and drug compounds for a range of immune-related disorders. ${ }^{15}$ These data suggest that characterizing the interaction and dynamic relationship between genes within implicated modules within a gene coexpression network-based paradigm can identify and prioritize genes that may serve as effective targets for therapeutic intervention.

Coexpression networks can also be used to model the effect of a drug compound on a group of functionally related genes. 
A

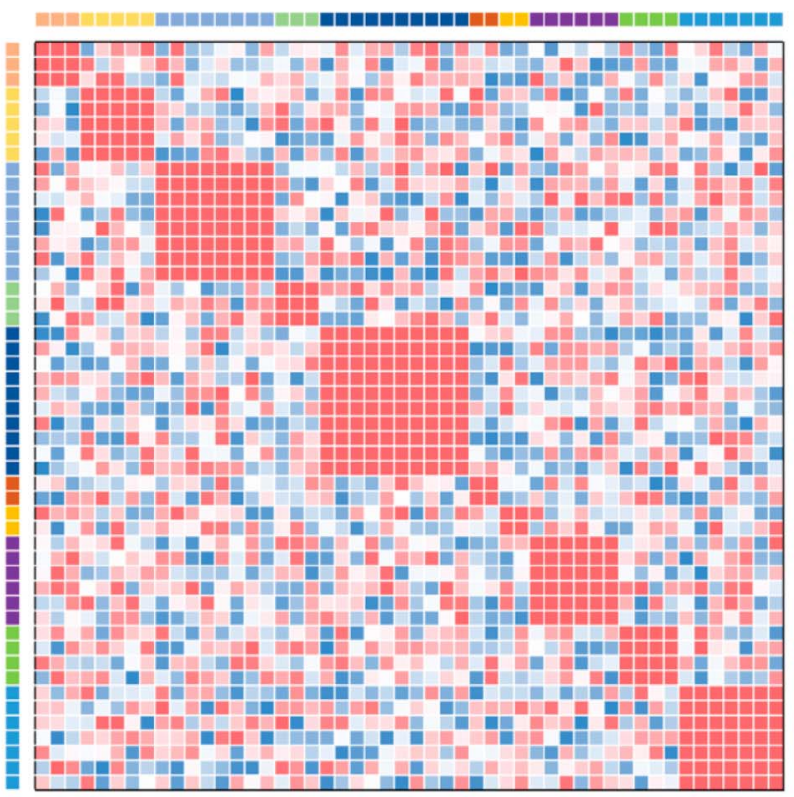

B
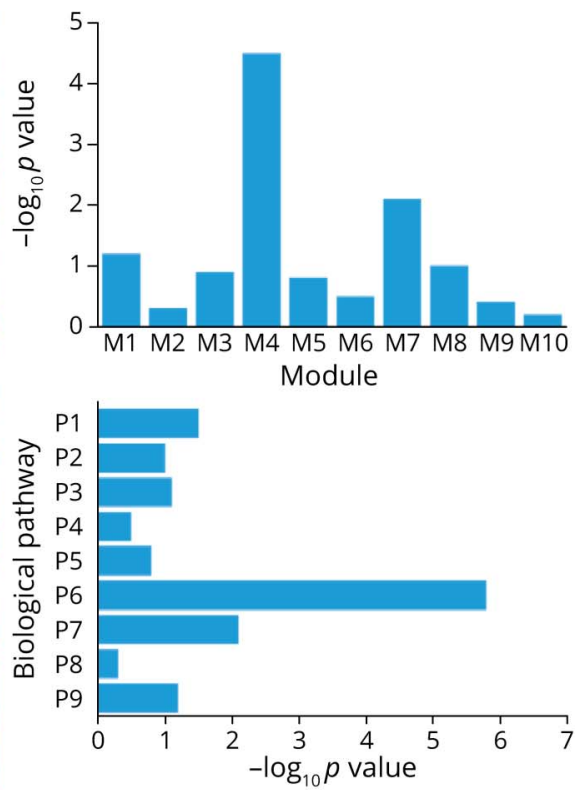

C

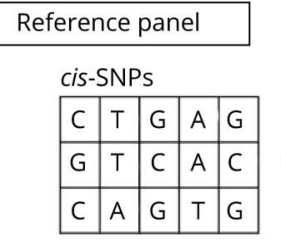

Reference panel

cis-SNPs
\begin{tabular}{|l|l|l|l|l|}
\hline C & T & G & A & G \\
\hline G & T & C & A & C \\
\hline C & A & G & T & G \\
\hline
\end{tabular}

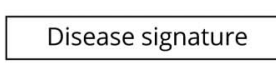

1

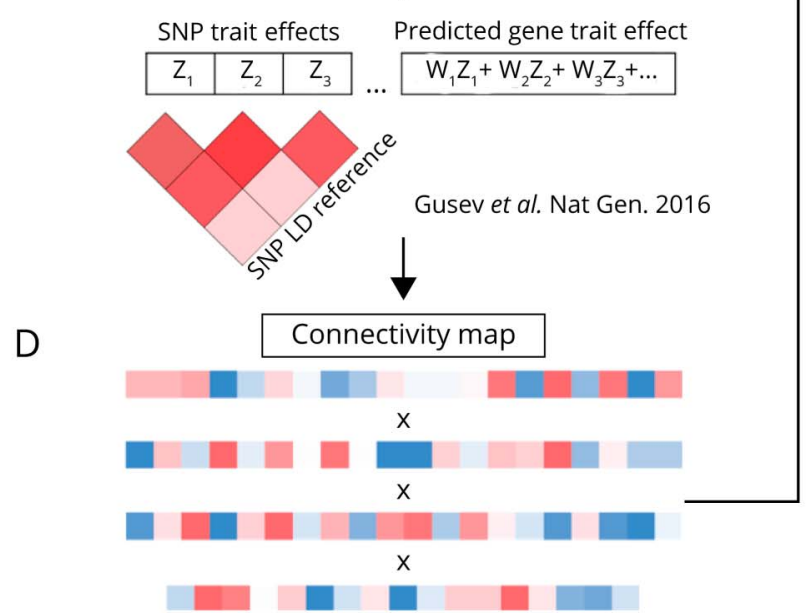

E

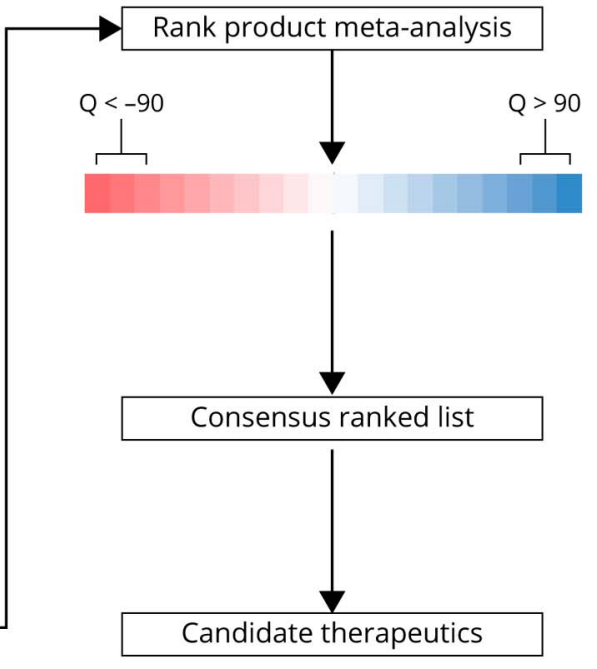

(A) For each tissue, perform a weighted gene co-expression analysis to identify modules of highly correlated genes. (B) Test for the enrichment of Alzheimer's disease association signals within tissue-specific gene co-expression networks. Assess the functional relevance of enriched modules by performing a biological pathway analysis of the modular genes. (C) Use S-PrediXcan to impute genetically regulated levels of gene expression for modular genes. All genes within the enriched module are separated into up-regulated and down-regulated gene sets. (D) Integrate the Alzheimer disease gene sets with the CMap database to identify compounds that are predicated to "normalise" the Alzheimer disease-associated signature. (E) Generate a ranked list of drug repositioning candidates and mechanism of action categories.

For example, the Connectivity Map (CMap) ${ }^{16}$ contains gene expression signatures resulting from genetic and pharmacologic perturbagens measured across multiple cell types. Drug-gene signatures-that is, gene expression changes following a genetic or pharmacologic perturbagen—can be integrated with disease-associated gene expression changes to identify existing compounds that might normalize gene expression. Characterizing the complex interactions 
Table 1 Gene-Set Enrichment Analysis and Biological Pathway Analysis of Alzheimer Disease Modules Across 13 Brain Tissues in GTEx

\begin{tabular}{|c|c|c|c|c|c|c|c|c|}
\hline \multirow[b]{2}{*}{ Tissue } & \multicolumn{5}{|c|}{ Gene-set enrichment analysis } & \multicolumn{3}{|c|}{ Biological pathway analysis } \\
\hline & $\mathrm{N}$ genes & Beta & SE & $p$ Value & p Adjust & Term & Term name & $p$ Cor \\
\hline Amygdala & 630 & 0.157 & 0.0351 & 3.80E-06 & $5.60 \mathrm{E}-05$ & GO:0002376 & Immune system process & $2.48 \mathrm{E}-73$ \\
\hline Anterior cingulate cortex BA24 & 353 & 0.164 & 0.047 & 2.34E-04 & $4.50 \mathrm{E}-03$ & GO:0006955 & Immune response & $4.54 \mathrm{E}-78$ \\
\hline Caudate basal ganglia & 393 & 0.143 & 0.0442 & $6.28 \mathrm{E}-04$ & $1.01 \mathrm{E}-02$ & GO:0002376 & Immune system process & $7.84 \mathrm{E}-73$ \\
\hline Cerebellar hemisphere & 197 & 0.248 & 0.0635 & 4.78E-05 & 7.00E-04 & GO:0006955 & Immune response & $2.08 \mathrm{E}-50$ \\
\hline Cerebellum & 103 & 0.425 & 0.0868 & $4.78 \mathrm{E}-07$ & $1.58 \mathrm{E}-05$ & GO:0002376 & Immune system process & $1.60 \mathrm{E}-32$ \\
\hline Cortex & 233 & 0.226 & 0.0567 & 3.32E-05 & $3.00 \mathrm{E}-04$ & GO:0006955 & Immune response & $1.64 \mathrm{E}-67$ \\
\hline Frontal cortex BA9 & 420 & 0.13 & 0.0423 & $1.02 \mathrm{E}-03$ & $1.90 \mathrm{E}-02$ & GO:0006955 & Immune response & $1.14 \mathrm{E}-76$ \\
\hline Hippocampus & 485 & 0.212 & 0.0395 & $3.98 \mathrm{E}-08$ & 7.60E-07 & GO:0002376 & Immune system process & $1.12 \mathrm{E}-95$ \\
\hline Hypothalamus & 768 & 0.191 & 0.0315 & $7.53 \mathrm{E}-10$ & $6.68 \mathrm{E}-08$ & GO:0006955 & Immune response & $1.83 \mathrm{E}-96$ \\
\hline Nucleus accumbens basal ganglia & 463 & 0.171 & 0.0411 & $1.59 \mathrm{E}-05$ & 4.00E-04 & GO:0006955 & Immune response & $9.69 \mathrm{E}-81$ \\
\hline Putamen basal ganglia & 352 & 0.175 & 0.0469 & $9.61 \mathrm{E}-05$ & $1.40 \mathrm{E}-03$ & GO:0006955 & Immune response & $5.95 \mathrm{E}-72$ \\
\hline Spinal cord cervical c-1 & 1,205 & 0.0915 & 0.0248 & 1.10E-04 & $1.70 \mathrm{E}-03$ & GO:0002376 & Immune system process & $5.86 \mathrm{E}-77$ \\
\hline Substantia nigra & 888 & 0.133 & 0.0291 & 2.44E-06 & 3.94E-05 & GO:0002376 & Immune system process & $3.14 \mathrm{E}-88$ \\
\hline
\end{tabular}

Abbreviations: Beta = test statistic from the gene-set enrichment analysis in MAGMA; GO = Gene Ontology; GTEx = Genotype-Tissue Expression; N Genes = number of genes in module; $p$ adjust $=p$ value corrected for gene size, gene density, and gene correlation; $p$ cor $=p$ value corrected for correlated structure of GO terms and corresponds to an experiment-wide threshold of $\alpha=0.05 ; \mathrm{SE}$, standard error of the test statistic.

See eTable 2, links.Iww.com/NXG/A452, for a complete list of enriched biological pathways for the immune system-related modules.

between genes in a network-based framework may identify targets for potential treatments through computational drug repositioning. In the present study, we have developed a novel computational drug repositioning approach that integrates tissue-specific gene coexpression networks with Alzheimer association signals and drug-gene signature data to identify and prioritize drug compounds that target disease processes.

\section{Methods}

\section{Alzheimer Disease GWAS Summary Statistics}

Detailed methods, including a description of population cohorts, quality control of raw SNP genotype data, and association analyses for the Alzheimer disease GWAS, are described in detail elsewhere. ${ }^{2}$ The Alzheimer disease GWAS was performed in a three-stage meta-analysis. The first phase consisted of 24,087 Alzheimer cases and 55,058 controls collected by the Alzheimer disease working group of the Psychiatric Genomics Consortium, the International Genomics of Alzheimer's Project, and the Alzheimer's Disease Sequencing Project. All cases in phase 1 received clinical confirmation of late-onset Alzheimer disease. The second phase included 47,793 proxy cases and 328,320 proxy controls from the UK Biobank (UKBB); proxy cases were defined as individuals with one or both parents diagnosed with Alzheimer disease, whereas proxy controls were defined as individuals with parents who do not have Alzheimer disease. Phase 3 involved the meta-analysis of phase 1 and phase 2 cohorts, the results of which were tested for replication in an additional independent case-control sample from deCODE (6,593 Alzheimer cases and 174,289 controls). Raw genotype data for each cohort were processed according to a standardized quality control pipeline. ${ }^{2}$ Logistic regression association tests were performed on imputed marker dosages and binary phenotypes in phase 1 , and linear regression for variables treated as continuous outcomes (the number of parents with Alzheimer disease) in phase 2 . For phase 1 phenotypes, the association tests were adjusted for sex, batch, and the first 4 principal components, with age also included as a covariation in the Alzheimer-PGC cohort. For phase 2 (UKBB) data, age, sex, batch, and assessment center were included as covariates. Summary statistics for 13,367,301 autosomal SNPs from phase 3 of the analyses described in reference $2(\mathrm{~N}$ samples $=$ $455,258)$ were made available by the Complex Trait Genetics Laboratory at VU University and VU Medical Centre, Amsterdam, and were used in our study.

\section{Identification of Gene Coexpression Modules}

We downloaded preprocessed and normalized gene expression data for 13 brain tissues collected by the GTEx project (gtexportal.org) (version 7). The expression data were filtered to include genes with 10 or more tissue donors with expression estimates $>0.1$ Reads Per Kilobase of transcript, per Million mapped reads (RPKM) and an aligned 
Figure 2 Gene Overlap (A) and Coexpression Preservation (B) Between Modules Enriched With Alzheimer Disease Association Signals

A

Anterior cingulate cortex BA24

Caudate basal ganglia

Cerebellar hemisphere

Cerebellum

Cortex

Frontal cortex BA9

Hippocampus

Hypothalamus

Nucleus accumbens basal ganglia

Putamen basal ganglia

Spinal cord cervical c-1

Substantia nigra

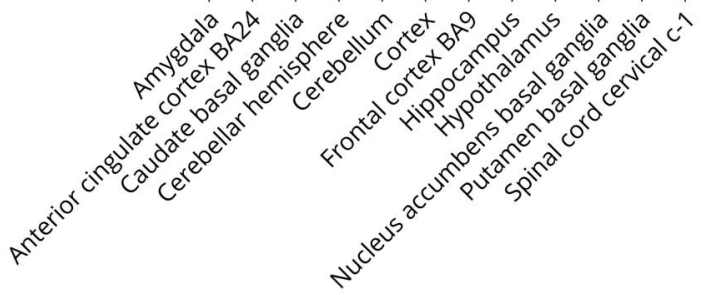

B

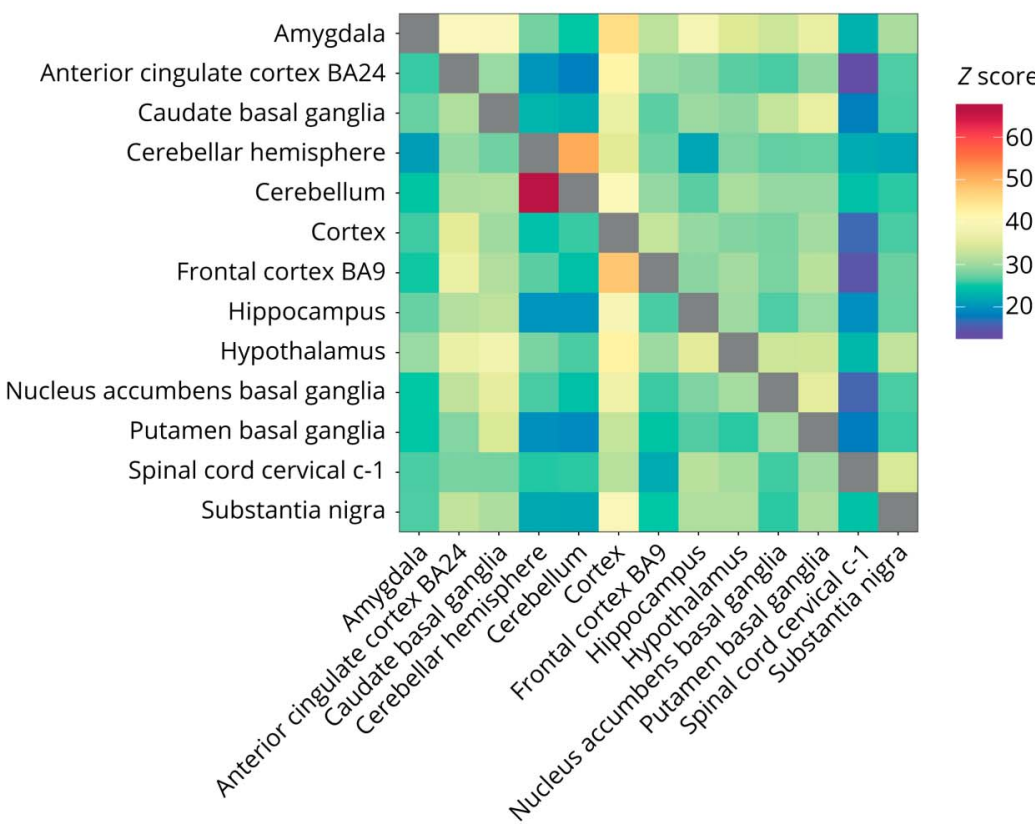

(A) The number of overlapping genes across tissuespecific modules is represented by the legend color scale. Blue represents the lowest gene overlap, and red represents the highest gene overlap. (B) The preservation of modular connectivity across tissues is represented by the legend color scale. A Z score greater than 10 (light blue-green) suggests that there is strong evidence that a module is preserved between the reference and test network modules, whereas a value between 2 and 10 indicates weak to moderate preservation, and a value less than 2 indicates no preservation (dark blue). All preservation Z scores were above 10 (minimum $Z=13.96$ [between spinal cord cervical c-1 and anterior cingulate cortex]), indicating strong preservation of modular connectivity across brain tissues/regions.

read count of a least 6 within each tissue. The distribution of RPKMs in each tissue sample was quantile transformed using the average empirical distribution observed across all samples. Finally, the gene expression values for each gene in each tissue were transformed to the quantiles of the standard normal distribution.

The construction of gene coexpression modules followed a protocol previously described by our laboratory. ${ }^{11}$ We used the weighted gene coexpression network analysis (WGCNA) package in $\mathrm{R} v 3.5 .1^{10}$ to build gene coexpression networks for 13 GTEx brain tissues. First, we computed an unsigned pairwise correlation matrix from the GTEx gene expression values using Pearson product-moment correlation coefficient. For each correlation matrix, we selected an appropriate softthresholding value in WGCNA by plotting the strength of correlation against a range (2-20) of soft threshold powers. We calculated network adjacency for each correlation matrix using the appropriate soft-threshold power and normalized each adjacency to generate a topological overlap matrix. Hierarchical 
Table 2 Number (Proportion) of Drug Compounds With Significant (s-90) Connectivity Scores Across 13 Brain Tissues

\begin{tabular}{|c|c|c|c|c|c|c|c|c|c|c|c|c|}
\hline \multirow[b]{2}{*}{ Tissue } & \multicolumn{3}{|c|}{ Gene input $(\mathrm{N})$} & \multicolumn{9}{|c|}{ Number (proportion) of significant connectivity scores by cell type } \\
\hline & Total & Up & Dn & A375 & A549 & HA1E & HCC515 & HEPG2 & HT29 & MCF7 & PC3 & VCAP \\
\hline Amygdala & 34 & 18 & 16 & $93(0.03)$ & $53(0.02)$ & $62(0.02)$ & $100(0.04)$ & $43(0.02)$ & $108(0.04)$ & $37(0.01)$ & $74(0.03)$ & $55(0.02)$ \\
\hline Caudate & 31 & 18 & 13 & $51(0.02)$ & $22(0.01)$ & $77(0.03)$ & $94(0.04)$ & $46(0.02)$ & $58(0.02)$ & $20(0.01)$ & $31(0.01)$ & $28(0.01)$ \\
\hline Frontal cortex & 27 & 18 & 9 & $93(0.03)$ & $51(0.02)$ & $59(0.02)$ & $71(0.03)$ & $60(0.03)$ & $55(0.02)$ & $36(0.01)$ & $48(0.02)$ & $28(0.01)$ \\
\hline Hippocampus & 32 & 19 & 13 & $58(0.02)$ & $38(0.01)$ & $44(0.02)$ & $51(0.02)$ & $55(0.03)$ & $64(0.02)$ & $20(0.01)$ & $40(0.01)$ & $22(0.01)$ \\
\hline Hypothalamus & 49 & 25 & 24 & $82(0.03)$ & $26(0.01)$ & $52(0.02)$ & $43(0.02)$ & $43(0.02)$ & $63(0.02)$ & $35(0.01)$ & $34(0.01)$ & $18(0.01)$ \\
\hline Nucleus accumbens & 26 & 11 & 15 & $64(0.02)$ & $43(0.02)$ & $47(0.02)$ & $52(0.02)$ & $47(0.02)$ & $53(0.02)$ & $24(0.01)$ & $31(0.01)$ & $19(0.01)$ \\
\hline Spinal cord cervical & 81 & 41 & 40 & $41(0.01)$ & $38(0.01)$ & $28(0.01)$ & $67(0.03)$ & $35(0.02)$ & $53(0.02)$ & $25(0.01)$ & $19(0.01)$ & $51(0.02)$ \\
\hline Substantia nigra & 36 & 18 & 18 & $89(0.03)$ & $33(0.01)$ & $76(0.03)$ & $74(0.03)$ & $52(0.03)$ & $52(0.02)$ & $15(0.01)$ & $29(0.01)$ & $27(0.01)$ \\
\hline
\end{tabular}

Abbreviations: $\mathrm{CMap}=$ Connectivity Map; $\mathrm{Dn}=$ number of downregulated genes; $\mathrm{N}=$ total number of genes uploaded to $\mathrm{CMap}$; Up = number of upregulated genes.

Only genes with reliably imputed genetically regulated gene expression were included in the CMap analysis.

clustering was performed on each topological overlap matrix using average linkage, with one minus the topological overlap matrix as the distance measure. The hierarchical cluster tree was cut into gene modules using the dynamic tree cut algorithm, ${ }^{17}$ with a minimum module size of 50 genes. For each module, we calculated the first principal component the gene expression values (known as an eigengene) and merged modules if the correlation between their eigengenes was greater or equal to 0.8 .

To assess the comparability of our module assignments to postmortem Alzheimer disease brain samples, we cross-tabulated our module assignments with those generated by Morabito et al. ${ }^{18}$ Morabito and colleagues used WGCNA to cluster 1,268 postmortem Alzheimer disease brain tissue gene expression data from 3 different studies - the Mayo Clinic Brain Bank (temporal cortex); Religious Orders Study and Memory and Aging Project (prefrontal cortex); and the Mount Sinai School of Medicine study (parahippocampal gyrus, inferior frontal gyrus, superior temporal gyrus, and frontal pole).

\section{Gene-Set Analysis of Gene Coexpression Modules}

The gene-set enrichment analysis of gene coexpression modules followed a protocol previously described by our laboratory. ${ }^{11}$ First, we used MAGMA v1.07 ${ }^{19}$ to (1) identify Alzheimer disease risk genes and (2) identify coexpression modules enriched with Alzheimer risk genes using gene-set analysis. The gene-based test of MAGMA assigns SNPs to genes within a predefined genomic window (35 kb upstream or $10 \mathrm{~kb}$ downstream of a gene body) and calculates a genebased statistic based on the sum of the assigned SNP $-\log (10)$ $p$ values while accounting for linkage disequilibrium (LD). To identify coexpression modules enriched with Alzheimer disease risk genes, we performed a competitive gene-set analysis in MAGMA. The gene-set analysis tests whether the genes in a gene coexpression module have a greater number of Alzheimer risk genes compared with other modules than expected by chance while accounting for gene size and gene density. We used an adaptive permutation procedure $(\mathrm{N}=$ 10,000 permutations) to correct for multiple testing (false discovery rate $<0.05$ ). The 1000 Genomes European reference panel (phase 3) was used to account for LD between SNPs.

\section{Biological Characterization of Alzheimer- Associated Gene Expression Modules}

We performed functional enrichment analysis for each module using g:Profiler (biit.cs.ut.ee/gprofiler/). ${ }^{20}$ Gene symbols within tissue-specific modules were used as input, and the gene universe was restricted to annotated genes. We tested for the overrepresentation of modular genes in Gene Ontology biological processes and Reactome biological pathways. The $\mathrm{g}$ :Profiler algorithm uses a Fisher 1-tailed test for gene pathway enrichment, which tests the probability a given gene is both a member of a coexpression module and particular biological pathway or process. Multiple testing correction was performed using g:SCS to account for the correlated structure of biological annotation terms, corresponding to an experiment-wide threshold of $\alpha=0.05$.

\section{Overlap and Preservation of Gene Coexpression Networks Across Tissues}

We assessed the module overlap and preservation of coexpression patterns across tissue-specific coexpression modules. Module overlap was calculated as the number and proportion of genes present in each pairwise tissue comparison $(\mathrm{N}=78)$. Module preservation was calculated using the modulePreservation function implemented in WGCNA. ${ }^{21}$ The module preservation function assesses the similarity of coexpression patterns across tissue-specific modules. We used the Zsummary statistic to represent preservation; a Zsummary 
Table 3 Number and Distribution of Connectivity Scores by Mechanism of Action

\begin{tabular}{|c|c|c|c|c|c|}
\hline \multirow[b]{2}{*}{ MOA } & \multirow{2}{*}{$\begin{array}{l}\text { Drugs } \\
\text { (N) }\end{array}$} & \multirow{2}{*}{$\begin{array}{l}\text { Genes } \\
\text { (N) }\end{array}$} & \multicolumn{3}{|c|}{ Score quantile } \\
\hline & & & 25th & 50th & 75th \\
\hline $\begin{array}{l}\text { Acetylcholine receptor } \\
\text { antagonist }\end{array}$ & 35 & 46 & -51.50 & -15.27 & 28.48 \\
\hline $\begin{array}{l}\text { Adrenergic receptor } \\
\text { agonist }\end{array}$ & 41 & 49 & -44.59 & -4.77 & 35.22 \\
\hline $\begin{array}{l}\text { Adrenergic receptor } \\
\text { antagonist }\end{array}$ & 52 & 117 & -44.84 & -7.18 & 33.42 \\
\hline ATPase inhibitor & 13 & 56 & -54.54 & -19.65 & 20.70 \\
\hline $\begin{array}{l}\text { Bacterial wall } \\
\text { synthesis inhibitor }\end{array}$ & 22 & 40 & -45.14 & -0.31 & 41.56 \\
\hline $\begin{array}{l}\text { Calcium channel } \\
\text { blocker }\end{array}$ & 24 & 131 & -46.51 & -12.90 & 28.33 \\
\hline $\begin{array}{l}\text { Cyclooxygenase } \\
\text { inhibitor }\end{array}$ & 51 & 152 & -36.42 & -3.84 & 30.63 \\
\hline $\begin{array}{l}\text { Dopamine receptor } \\
\text { agonist }\end{array}$ & 23 & 53 & -45.96 & -10.81 & 31.12 \\
\hline $\begin{array}{l}\text { Dopamine receptor } \\
\text { antagonist }\end{array}$ & 59 & 163 & -33.93 & -2.57 & 29.98 \\
\hline EGFR inhibitor & 22 & 71 & -43.57 & 3.65 & 42.91 \\
\hline $\begin{array}{l}\text { Estrogen receptor } \\
\text { agonist }\end{array}$ & 18 & 87 & -51.11 & -23.08 & 26.89 \\
\hline $\begin{array}{l}\text { Estrogen receptor } \\
\text { antagonist }\end{array}$ & 9 & 102 & -62.86 & -30.98 & 15.64 \\
\hline FLT3 inhibitor & 13 & 98 & -66.99 & -20.26 & 43.39 \\
\hline $\begin{array}{l}\text { GABA receptor } \\
\text { antagonist }\end{array}$ & 10 & 33 & -52.37 & -14.13 & 32.92 \\
\hline $\begin{array}{l}\text { GABA receptor } \\
\text { modulator }\end{array}$ & 8 & 40 & -49.25 & 6.70 & 41.38 \\
\hline $\begin{array}{l}\text { Glucocorticoid } \\
\text { receptor agonist }\end{array}$ & 31 & 160 & -50.86 & -16.13 & 32.40 \\
\hline $\begin{array}{l}\text { Glutamate receptor } \\
\text { antagonist }\end{array}$ & 31 & 103 & -49.73 & -10.92 & 38.69 \\
\hline HDAC inhibitor & 19 & 41 & -28.95 & 19.62 & 51.30 \\
\hline $\begin{array}{l}\text { Histamine receptor } \\
\text { antagonist }\end{array}$ & 39 & 96 & -40.75 & -7.57 & 30.32 \\
\hline JAK inhibitor & 11 & 26 & -46.71 & -9.44 & 42.31 \\
\hline MEK inhibitor & 12 & 38 & -38.30 & -7.79 & 30.77 \\
\hline $\begin{array}{l}\text { Phosphodiesterase } \\
\text { inhibitor }\end{array}$ & 31 & 104 & -38.48 & -4.79 & 29.22 \\
\hline PPAR receptor agonist & 19 & 85 & -48.77 & 6.40 & 46.45 \\
\hline $\begin{array}{l}\text { Progesterone receptor } \\
\text { agonist }\end{array}$ & 13 & 81 & -53.21 & -22.36 & 35.57 \\
\hline $\begin{array}{l}\text { Protein synthesis } \\
\text { inhibitor }\end{array}$ & 11 & 47 & -65.55 & -27.79 & 35.74 \\
\hline $\begin{array}{l}\text { Retinoid receptor } \\
\text { agonist }\end{array}$ & 10 & 107 & -48.62 & -12.89 & 26.72 \\
\hline $\begin{array}{l}\text { Serotonin receptor } \\
\text { agonist }\end{array}$ & 29 & 67 & -36.08 & 1.07 & 37.78 \\
\hline
\end{tabular}

Table 3 Number and Distribution of Connectivity Scores by Mechanism of Action (continued)

\begin{tabular}{llllll}
\hline & Drugs & Genes & \multicolumn{4}{l}{ Score quantile } & \\
\cline { 5 - 7 } MOA & (N) & (N) & 25th & 50th & 75th \\
\hline $\begin{array}{l}\text { Serotonin receptor } \\
\text { antagonist }\end{array}$ & 60 & 157 & -42.09 & -4.89 & 34.09 \\
\hline $\begin{array}{l}\text { Sodium channel } \\
\text { blocker }\end{array}$ & 23 & 98 & -38.84 & -6.34 & 24.14 \\
\hline $\begin{array}{l}\text { Tyrosine kinase } \\
\text { inhibitor }\end{array}$ & 14 & 87 & -44.91 & -10.65 & 46.80 \\
\hline \begin{tabular}{l} 
VEGFR inhibitor \\
\hline
\end{tabular} & 18 & 91 & -54.58 & 6.62 & 41.19 \\
\hline
\end{tabular}

Abbreviations: Drugs $(\mathrm{N})=$ number of drugs within each MOA category; Genes $(N)=$ number of target genes from drug bank and the drug-gene interaction database within each MOA; $\mathrm{MOA}=$ mechanism of action

Score quantile shows the 25th, 50th, and 75th quantiles for connectivity scores within each MOA.

statistic greater than 10 indicates strong modular preservation across tissues, whereas a statistic between 2 and 10 indicates weak to moderate modular preservation, and a statistic less than 2 suggests no preservation.

\section{Computational Drug Repositioning}

Our computational drug repositioning analysis tests the predicted effect of a drug compound on dysregulated gene expression modules underlying Alzheimer disease. First, we used S-PrediXcan (version 0.6.10) to estimate the magnitude and direction of gene expression changes associated with Alzheimer disease. This approach integrates eQTL information with GWAS summary statistics to estimate the effect of genetic variation underlying a disease or trait on gene expression. ${ }^{12}$ We used eQTL information (expression weights) from 13 tissues generated by the GTEx project (v7) 12 and LD information from the 1000 Genomes Project Phase $3{ }^{22}$ These data were processed with beta values and standard errors from the GWAS of Alzheimer disease to estimate the expression-GWAS association statistic. For each GTEx tissue, we extracted the S-PrediXcan $\mathrm{Z}$ scores for genes within modules enriched with Alzheimer disease association signals and created 2 lists containing genes with either upregulated or downregulated expression. Second, the gene lists were used as the basis of drug repositioning using drug gene signatures downloaded from the CMap. ${ }^{16}$ For each gene list and unique compound in CMap, we calculated a connectivity score based on a modified Kolmogorov-Smirnov score, which summarizes the transcriptional relationship to the Alzheimer disease module genes. The connectivity score is a standardized statistic ranging from -100 to 100 , where a highly negative score indicates predicted expression effect from S-PrediXcan, and the drug-gene signatures are opposing (i.e., genes that are upregulated in disease cases are downregulated by the compound and vice versa). Third, we selected compounds with connectivity scores of -90 and lower (indicating a significant effect of a compound on the Alzheimer disease expression signature). The selected 


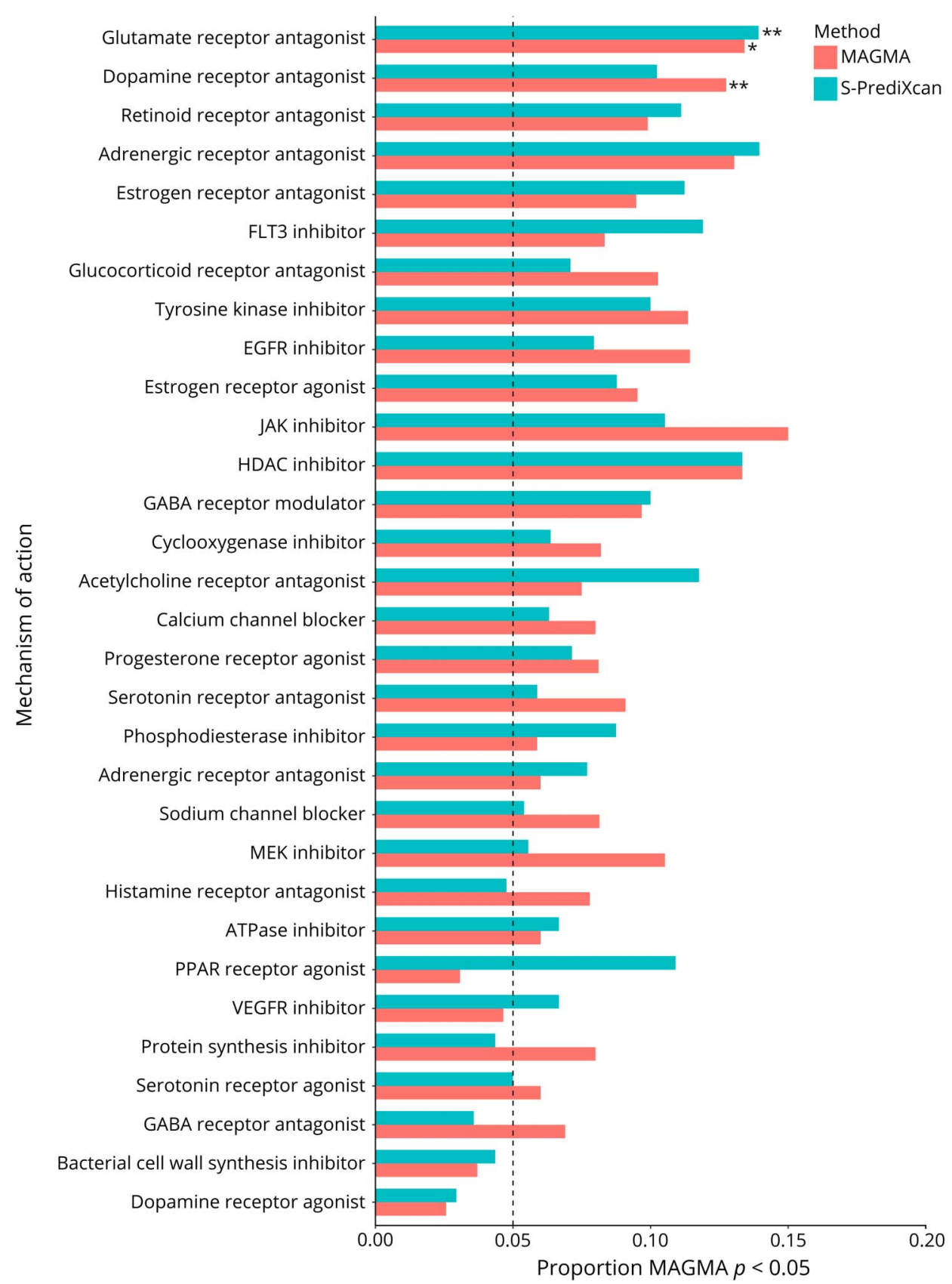

A single asterisk indicates nominal (Fisher exact test, $p<0.05$ ) enrichment of smaller than expected $(p<0.05) p$ values within a drug category. A double asterisk indicates significant enrichment of smaller than expected $p$ values within a drug category after multiple testing correction for the number of MOA categories $(p<0.0016)$. MOA = mechanism of action. compounds were mapped to their target genes using drugtarget information curated from DrugBank ${ }^{23}$ and the DrugGene Interaction database ${ }^{24}$ and assign to mechanism of action (MOA) categories to identify chemogenomic trends. To assess the disease specificity of the CMap enrichments, we performed our pipeline using GWAS summary statistics for schizophrenia, ${ }^{25}$ a brain-related neuropsychiatric disorder with an immune component. Top-ranked compounds from schizophrenia and Alzheimer disease were placed in a contingency table and assessed for significant overlap (i.e., significant in both schizophrenia and Alzheimer disease) using the hypergeometric test.
To assess how drugs that have undergone a clinical trial for Alzheimer disease or its associated symptoms were prioritized by our repositioning pipeline, we downloaded all available clinical trial data for Alzheimer disease from ClinicalTrials. gov, resulting in 2,565 records. We subset these data to drug compound interventions, leaving 1,707 records. Finally, we intersected the clinical trial drug list with repositioning information from our study and summarized the connectivity scores for each drug.

To test the significance of the Alzheimer disease perturbational enrichments (i.e., ensuring that significant results are 
A. Glutamate receptor antagonists

$\square$ I-689560 $\square$ Memantine $\square$ Dextromethorphan

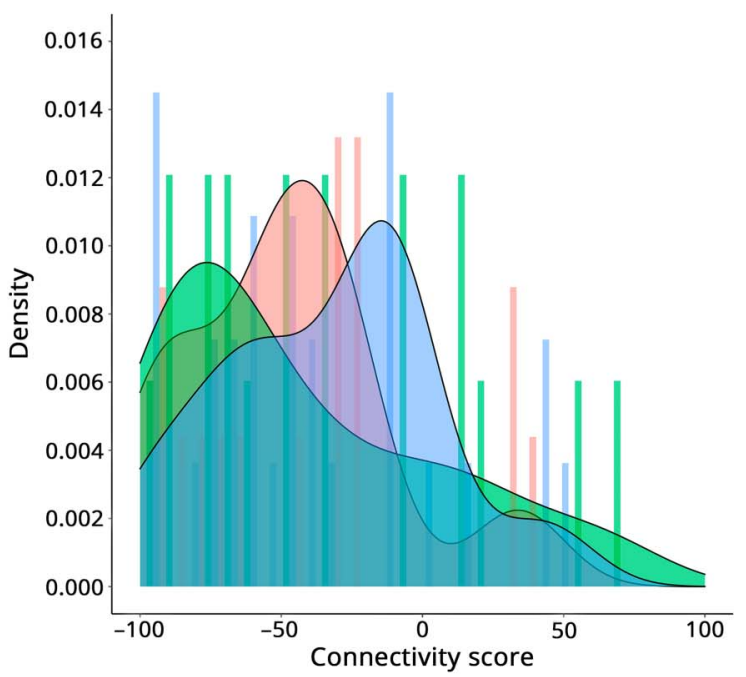

B. Dopamine receptor antagonists

$\square$ Methylergometrine $\square$ Ziprasidone $\square$ Thiothixene

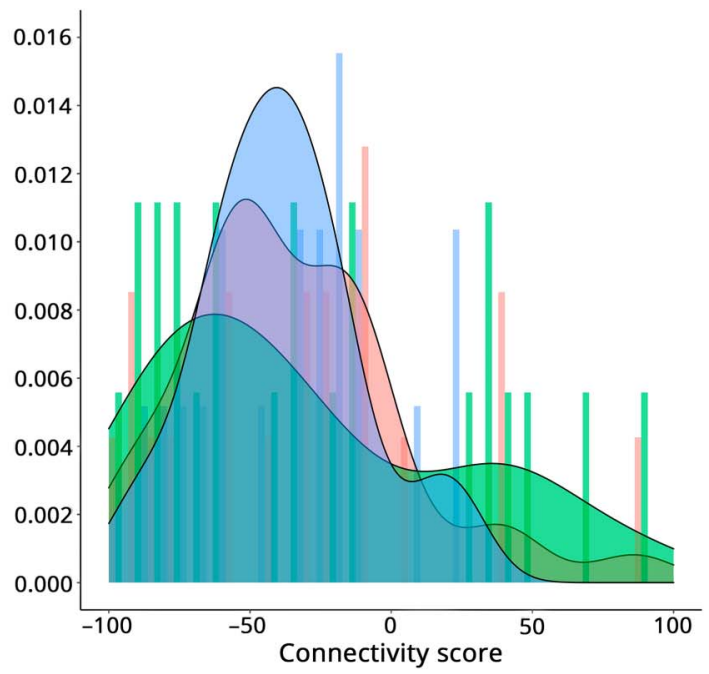

The density plots and histograms show the distribution of connectivity scores across cell types and tissues for each top-ranked compound. MOA = mechanism of action.

not due to random chance), we grouped the observed coexpression values for pairs of genes from a single tissue (amygdala) into 100 bins. We randomly sampled genes across bins, selecting the same number of gene coexpression values from each bin as the observed data. This stratified method of sampling was performed to ensure that the observed and permuted data were matched on connectivity. The permuted coexpression modules were uploaded to CMap using the clue API client, and connectivity scores for each compound were extracted from the output files. We calculated empirical $p$ values for observed compounds with connectivity scores smaller than -90 by counting the number of times the same compound from the permuted data had a connectivity score smaller than -90. A compound with an empirical $p$ value $<0.05$ is unlikely to be prioritized by random chance.

\section{Standard Protocol Approvals, Registrations, and Patient Consents}

The GTEx v7 data were downloaded from the publicly available GTEx data portal (gtexportal.org/home/datasets). Data access followed the guidelines in the Data Use Certification Agreement. All study protocols regarding human subjects have been approved by their local institutional review board and were compliant with Health Insurance Portability and Accountability Act (HIPAA) regulations. Informed written consent was given by family decision makers of deceased donors. ${ }^{26}$

\section{Data Availability}

All data generated during this study are included in this published article and its supplementary information files. Original raw data can be made available on request.

\section{Results}

Figure 1 provides an overview of our analytical pipeline. Step 1: For 13 brain tissues in GTEx, we performed a weighted gene coexpression analysis to identify modules of highly correlated genes. Step 2: We test for the enrichment of Alzheimer disease association signals within tissue-specific gene coexpression networks and assess the functional relevance of enriched modules by performing a biological pathway analysis of the modular genes. Step 3: We use S-PrediXcan to impute genetically regulated levels of gene expression for modular genes, which provides a direction of effect of dysregulated gene expression in Alzheimer disease (Alzheimer disease signature). All genes within the enriched module are separated into upregulated and downregulated gene sets. Step 4: We interrogate the CMap database for drug compounds with negative connectivity scores that are predicated to normalize the Alzheimer disease-associated signature. Step 5: We generate a ranked list of drug repositioning candidates and MOA categories that show enrichment of nominally significant $(p<$ $0.05)$ gene-based associations (MAGMA and S-PrediXcan) across compounds within each category.

\section{Alzheimer Disease Risk Genes Are Enriched in Gene Coexpression Modules Associated With the Immune System}

Our MAGMA gene-based analysis of existing GWAS data revealed 74 genes significantly associated with Alzheimer disease after multiple testing correction $\left(p<2.78 \times 10^{-6}\right)$ (eTable 1, links.lww.com/NXG/A451, and eFigure 1, links. lww.com/NXG/A463). We tested for the enrichment of genebased association in gene coexpression modules built from 13 
Table 4 Top-Ranked Glutamate and Dopamine Receptor Antagonists for Repositioning in Alzheimer Disease

\begin{tabular}{|c|c|c|c|c|c|}
\hline \multirow[b]{2}{*}{ Compound } & \multirow[b]{2}{*}{ MOA } & \multicolumn{4}{|c|}{ Connectivity score } \\
\hline & & Mean & Min & Max & $N \leq-90$ \\
\hline Methylergometrine & Dopamine receptor antagonist & -50.65 & -97.62 & -10.86 & 1 \\
\hline L-689560 & Glutamate receptor antagonist & -47.96 & -95.76 & 38.17 & 6 \\
\hline Memantine $^{a}$ & Glutamate receptor antagonist & -43.88 & -94.74 & 65.57 & 2 \\
\hline Ziprasidone & Dopamine receptor antagonist & -39.64 & -98.86 & 45.44 & 1 \\
\hline Thiothixene & Dopamine receptor antagonist & -38.43 & -92.71 & 23.85 & 1 \\
\hline Fluphenazine & Dopamine receptor antagonist & -30.93 & -95.07 & 62.63 & 1 \\
\hline Dextromethorphan & Glutamate receptor antagonist & -30.92 & -99.36 & 48.45 & 2 \\
\hline YM-298198 & Glutamate receptor antagonist & -21.14 & -94.32 & 83.77 & 1 \\
\hline N20C & Glutamate receptor antagonist & -20.32 & -94.04 & 76.00 & 2 \\
\hline Ifenprodil & Glutamate receptor antagonist & -16.50 & -92.86 & 68.01 & 2 \\
\hline Flupirtine & Glutamate receptor antagonist & -16.46 & -88.88 & 92.51 & 0 \\
\hline Felbamate & Glutamate receptor antagonist & -16.13 & -93.40 & 69.99 & 1 \\
\hline SCH-23390 & Dopamine receptor antagonist & -14.05 & -90.08 & 77.37 & 1 \\
\hline Clozapine & Dopamine receptor antagonist & -12.22 & -96.72 & 87.41 & 2 \\
\hline Droperidol & Dopamine receptor antagonist & -10.60 & -99.77 & 86.29 & 5 \\
\hline GR-103691 & Dopamine receptor antagonist & -10.45 & -96.67 & 87.93 & 3 \\
\hline SIB-1893 & Glutamate receptor antagonist & -9.39 & -97.26 & 84.33 & 3 \\
\hline NBQX & Glutamate receptor antagonist & -9.38 & -99.64 & 93.74 & 3 \\
\hline Iloperidone & Dopamine receptor antagonist & -9.06 & -97.64 & 84.81 & 1 \\
\hline Triflupromazine & Dopamine receptor antagonist & -8.49 & -99.29 & 64.73 & 1 \\
\hline
\end{tabular}

Abbreviations: CMap = Connectivity Map; MOA = mechanism of action.

$\mathrm{N} \leq-90$ shows the number of times a given drug compound had a connectivity score $\leq-90$ across tissues/CMap cell types.

${ }^{a}$ Memantine is currently used for the treatment of moderate-to-severe Alzheimer disease.

GTEx brain tissues. ${ }^{11}$ In each of the 13 tissues, a single gene module was enriched with Alzheimer disease risk genes (henceforth referred to as Alzheimer disease modules) (Table 1) (eTable 2, links.lww.com/NXG/A452). There was substantial sharing of genes across the tissue-specific Alzheimer disease modules. The modules comprised 103 (cerebellum) to 1,205 (spinal cord) genes; 87 genes were common across all modules and the proportion of shared genes in pairwise tissue comparisons ranged from $16 \%$ (amygdala and cerebellum) to 100\% (cerebellum and hypothalamus) (Figure 2A; eTable 3, links.lww.com/NXG/ A453). Gene pathway analyses found the enrichment of immune system pathways (e.g., immune system process in the brain amygdala, $p=2.48 \times 10^{-73}$, and immune response in the brain substantia nigra; $p=2.48 \times 10^{-88}$ ) within all Alzheimer modules (Table 1) (see eTable 4, links.lww.com/ NXG/A454, for a full list of biological pathway enrichments in the Alzheimer disease modules). We assessed the preservation (i.e., reproducibility) of the connectivity structure across brain tissues using the WGCNA modulePreservation algorithm. Strong modular preservation $(\mathrm{Z}$ score $\geq 10)$ was observed across all brain tissues (Figure $2 \mathrm{~B}$ ), suggesting that the connectivity structure (i.e., correlation) of genes is similar across brain tissues.

We also found nonenriched modules that harbored significant $\left(p<2.78 \times 10^{-6}\right)$ Alzheimer disease risk genes. For example, module M1 in the amygdala contained 2 Alzheimer disease risk genes, PICALM and BIN1, and was enriched for biological pathways related to myelination and neurogenesis. Furthermore, module M2 in the amygdala contained 8 risk genes (including APOC1) and was enriched with pathways related to synaptic signaling (eTable 5, links.lww.com/NXG/ A455). However, these modules were not statistically enriched with Alzheimer disease risk genes on a global level and did not replicate well across GTEx brain tissues. We therefore focused on the immune system-related modules for the computational repositioning analysis. 
We compared our gene coexpression modules, which were derived from brain tissue samples from healthy donors, with modules reported by Morabito et al., who derived their modules from postmortem Alzheimer disease brain tissue samples. We found an average of $54 \%$ of genes overlapping between our modules and a single postmortem module from Morabito et al., with nonoverlapping genes falling within an unassigned (gray) module (eTable 6, links.lww.com/NXG/ A456, and eTable 7, links.lww.com/NXG/A457). Importantly, the overlapping postmortem module was enriched with Alzheimer disease GWAS association signals as well as microglial cell markers and immune-related biological pathways. These data suggest that gene expression from nondiseased brain tissues coupled with imputation of genetically regulated gene expression may capture gene coexpression networks underlying Alzheimer disease.

\section{A Computational Drug Repurposing Analysis Identifies Drug Compounds for Further Analysis}

Our tissue-specific gene coexpression modules provide a useful substrate for the identification and prioritization of drugs that may normalize altered gene coexpression in Alzheimer disease. We used S-PrediXcan to identify genes whose genetically regulated expression is associated with genetic variation underlying Alzheimer disease (eTable 8, links.lww. com/NXG/A471). The use of genetically regulated gene expression removed unwanted environmental effects on gene expression (e.g., medication use) and thereby mitigates reverse causation. We assigned the S-PrediXcan $\mathrm{Z}$ score for the direction and magnitude of effect to all genes within Alzheimer disease risk modules and generated lists of upregulated and downregulated genes. The gene lists were used as input to the CMap, which computes a connectivity score based on the transcriptional relationship between the gene lists and observed drug-gene signatures across multiple cell types. Table 2 provides a summary of the number of upregulated and downregulated genes uploaded to CMap and the number and proportion of drug compounds with significant connectivity scores by brain tissue (a full list of compounds with significant connectivity scores [score $\leq-90$ ] is provided in eTable 9, links.lww.com/NXG/A458).

To identify drug categories associated with Alzheimer disease, we first assigned each drug compound to a MOA category (Table 3; eTable 10, links.lww.com/NXG/A459). We then tested for the enrichment of nominally significant $(p<0.05)$ gene-based associations (MAGMA and S-PrediXcan) across compounds within each category. Two categoriesglutamate receptor antagonists and dopamine receptor antagonists-harbored a larger proportion of nominally significant $p$ values for Alzheimer disease than expected by chance (Figure 3). We extracted top-ranked compounds (by mean connectivity score across all tissues and cell types) within significant MOAs and plotted the distribution of their connectivity scores (Figure 4). The top 3 glutamate receptor antagonists included memantine, commonly used to treat the symptoms of moderate-to-severe Alzheimer disease, and dextromethorphan, a compound with clinical efficacy for the treatment of agitation associated with Alzheimer disease, highlighting the utility of our approach. Top dopamine receptor antagonists included a number of antipsychotics (e.g., ziprasidone) that are used to treat aggression and behavioral issues in Alzheimer disease (Table 4). ${ }^{27}$ We also examined how drugs that have undergone a clinical trial for Alzheimer disease and/or its associated symptoms performed in the repositioning pipeline. Although their respective MOA categories were not enriched with Alzheimer disease association signals, top-ranked drug compounds that have undergone a clinical trial included naproxen (cyclooxygenase inhibitor), mirtazapine (serotonin receptor antagonist), and caffeine (phosphodiesterase inhibitor) (eTable 11, links.lww.com/ NXG/A460).

To assess the significance of drug-gene level results, we applied a permutation procedure (methods) using expression data from the amygdala - the tissue with the largest number of drug-gene associations. The results show that top-ranked compounds are unlikely to be due to correlated expression (eTable 12, links.lww.com/NXG/A461). We also ran our network-based pipeline with GWAS summary statistics for schizophrenia, a brain-related disorder with an immune component that is not genetically correlated with Alzheimer disease, as a negative control, and found no significant overlap (hypergeometric test) with our observed results for Alzheimer disease across cell types (eTable 13, links.lww.com/NXG/ A462). These observations strengthen the candidacy of potential Alzheimer therapeutics and illustrate the potential of CMap within a gene coexpression network framework to generate novel, unbiased hypotheses on the pharmacologic modulation of disease states.

\section{Discussion}

We developed a novel computational drug repositioning approach based on the integration of SNP genotype, tissuespecific gene coexpression patterns, and drug perturbation data. Computational drug repositioning provides a biologically valid approach to evaluate the predicted effect of drug compounds on cellular activity. We applied a tissuespecific network-based gene coexpression method to identify groups of highly correlated, functionally related genes associated with Alzheimer disease. Gene-based analyses of GWAS summary statistics were enriched in a single gene module in 13 brain tissues, each of which contained genes involved in the immune system and immune response. A computational drug repositioning analysis of genes within these tissue-specific Alzheimer modules identified drugs and broader mechanisms of action categories. Some of the identified compounds have been approved to treat Alzheimer disease and its associated symptoms (e.g., memantine). We also provide a list of plausible novel drug candidates for functional validation studies. Our results demonstrate that a tissue-specific approach to 
gene discovery in Alzheimer disease may not only identify candidate causal genes, tissues, and biological pathways but also targets for therapeutic intervention.

Neuroinflammation has an important role in the onset and progression of the pathologic changes underlying Alzheimer disease. Independent studies have identified immune-related proteins and cells in the proximity of $\beta$-amyloid plaques, ${ }^{28}$ for example, and epidemiologic reports suggested that antiinflammatory agents used to treat immune disorders, such as rheumatoid arthritis, decrease the risk of Alzheimer disease. ${ }^{29}$ It was not until the publication of a large-scale GWAS on Alzheimer that the first robust evidence for a causal association between neuroinflammation and disease onset was established. ${ }^{2}$ We performed a secondary analysis of the GWAS results, and the study of tissue-specific gene coexpression patterns allowed us to investigate a larger set of genes that might be implicated in disease based on network connectivity. We identified immune system-related tissuespecific modules (i.e., groups) of coexpressed genes that are both enriched with Alzheimer disease association signals and strongly preserved (i.e., replicated) across tissues.

Our gene coexpression networks, built from brain gene expression data from healthy individuals, showed good overlap with postmortem Alzheimer disease samples, which were also enriched with GWAS signals and immune system-related biological pathways. This suggests that coexpression patterns from nondiseased brain tissue followed by the integration of disease-associated genetically regulated gene expression may be used to identify groups of genes whose activity drives Alzheimer disease onset and progression. Furthermore, the diversity of sampled brain regions between GTEx and the data sets used by Morabito, which included samples from the temporal cortex, ${ }^{30}$ prefrontal cortex,${ }^{31}$ parahippocampal gyrus, inferior frontal gyrus, superior temporal gyrus, and frontal pole, $^{32}$ suggests that genetically regulated changes underlying Alzheimer disease may converge on neuroimmune networks operating across brain regions. Therefore, meaningful biological insights for Alzheimer disease may be derived from the integration of disease-associated genetic data with large numbers of nondiseased and non-tissue-specific brain samples, which are relatively easy to collect for a sufficiently powered study.

We further demonstrated the versatility of coexpression network-based methods with the application of a novel computational drug repositioning approach, where the imputed effect direction in Alzheimer disease for all genes within diseaseimplicated modules was used as input to CMap. This approach was taken under the biologically valid assumption that a drug compound not only alters the activity of a single target gene but the activity of multiple related genes through coregulation. ${ }^{33}$ Furthermore, by imputing gene expression effects from GWAS summary statistics, we focused only on genetically regulated gene expression effects, thereby removing unwanted variation on gene expression from environmental effects (e.g., medication use) as well as controlling for reverse causation. ${ }^{12}$ This approach identified drug compounds within disease relevant mechanisms of action that are predicted to normalize the expression of candidate causal genes in Alzheimer disease.

We identified 2 drug MOA categories enriched with smaller than expected Alzheimer disease association signals: glutamate receptor antagonists and dopamine receptor antagonists. Glutamate is present in higher levels in patients with Alzheimer disease. ${ }^{34}$ Increased glutamate in the brain is widely thought to promote neurotoxicity and neurodegeneration and may also may also trigger neuroinflammation in (genetically) susceptible individuals. ${ }^{35}$ Genetic studies strongly support a role of the immune system in Alzheimer disease pathophysiology, ${ }^{36}$ and risk genes are highly expressed in microglia-the primary immune cells of the brain. ${ }^{37,38}$ Therefore, glutamate may be an important link between the nervous and immune systems in Alzheimer disease onset and progression, with a central role for microglial cells, however, a functional mechanism has yet to be established. Dopamine receptor modulators are also used to treat some of the symptoms of Alzheimer disease, such as agitation and psychosis $^{39}$; however, a clear role of dopamine in Alzheimer pathophysiology has yet to be established. Nonetheless, dopamine is an important regulator of immune function and response in the brain, ${ }^{40}$ and microglial cells express functional dopamine receptors. Therefore, dopamine may also play a role in the crosstalk between immune and nervous systems in Alzheimer disease.

Top-ranked glutamate receptor antagonists included memantine, which is approved to treat the symptoms of moderateto-severe Alzheimer disease, ${ }^{41}$ and dextromethorphan, which is used to treat agitation associated with Alzheimer disease. ${ }^{39}$ Other highly ranked selective antagonists of glutamate receptors with potential neuroprotective effects included ifenprodil, shown to ameliorate amyloid- $\beta$ induced inhibition of synaptic transmission and hippocampal dysfunction, ${ }^{42}$ and flupirtine, a well-tolerated nonopioid analgesic drug with potential neuroprotective effects. ${ }^{43}$ Highly ranked dopamine receptor antagonists included methylergometrine, which has been shown to inhibit inflammasome degranulation under proinflammatory conditions $^{44}$ with potential therapeutic benefits for diseases with an inflammatory component, such as Alzheimer disease. While these drugs alleviate the symptoms of Alzheimer disease, it is not known if they target a causal gene or biological mechanism. Our results suggest that these drugs may indeed target a causal mechanism, given that the drug-gene signatures were derived from genetic data from Alzheimer disease cases and controls. The use of drug perturbation data may therefore refine our understanding of gene mechanisms underlying Alzheimer disease, in addition to potential therapeutic targets.

Genetic associations for Alzheimer disease are enriched in genomic regions that encode druggable gene targets. ${ }^{45}$ Computational repositioning is therefore a promising avenue for the translation of genetic associations to drug targets. So et al. ${ }^{46}$ used GWAS-imputed transcriptome profiles and the CMap algorithm to identify candidates for drug repositioning in neuropsychiatric disorders and identified several nonsteroidal anti-inflammatory drugs (NSAIDs), also known as 
cyclooxygenase inhibitors, with possible benefits in Alzheimer disease. We identified several NSAIDs with promising connectivity score distributions across cell types and tissues, including (for example) naproxen, which has shown mixed results for their protective effect from Alzheimer disease. ${ }^{47,48}$ However, we did not find enrichment of significant genebased association signals for Alzheimer disease within known gene targets of NSAIDs. We extend the analysis of So et al. with the use of a larger, more highly powered GWAS and network-based methods to implicate additional genes with potential relevance in Alzheimer disease pathology. A recently published study used genetic information and network-based methods to develop a priority index for drug target validation in immune-mediated traits. ${ }^{15}$ The priority index incorporated functional genomic information with protein-protein network connectivity information and was shown to successfully identify current therapeutics and prioritize alternative compounds for early-stage testing. Their network annotations, however, do not directly integrate genetic coexpression, but instead rely on disparate sources of protein interaction data to characterize gene connectivity. Our gene coexpression-based approach, on the other hand, directly anchors changes in genetically regulated gene expression to observed levels of coexpression between genes and arguably more closely represents underlying biological relationships.

The results of this study should be interpreted in view of the following limitations. First, we used GWAS summary statistics that included Alzheimer disease-by-proxy cases. Although proxy cases, based on parental diagnoses, show a high genetic correlation with clinically diagnosed cases, follow-up studies should be conducted using GWAS summary statistics from diagnosed Alzheimer disease studies. ${ }^{36}$ Second, we used gene expression data from bulk human brain tissue as single-cell expression data are not available in GTEx. Bulk brain tissue is not homogeneous with respect to individual cell types. As a result, true Alzheimer disease association signals may be diluted by nonspecific expression, or expression differences may simply reflect mosaic effects of different cell types. This is especially problematic for Alzheimer disease, where many of the risk genes are highly expressed in microglia cells which only account for around 3\% of the total brain cell population. ${ }^{49-51}$ RNA sequencing of individualized cells (known as single-cell RNA sequencing) may partition genetic signals to causal cell types and improve power to identify functional genes and mechanisms underlying $\mathrm{Alz}$ heimer disease and, in turn, improve the accuracy of drug positioning. ${ }^{9}$ Third, the CMap database does not contain druggene signatures for every approved and experimental drug. Importantly, 3 FDA acetylcholinesterase inhibitors used to treat the symptoms of Alzheimer disease (galantamine, rivastigmine, and donepezil) were missing from CMap. The absence of these compounds may explain why we did not observe significant enrichment of Alzheimer disease association signals within the acetylcholinesterase inhibitors MOA category. Fourth, our observed drug compound associations are derived from the combined effect of gene expression patterns within Alzheimer disease modules. Therefore, our analytical pipeline cannot identify individual drug-gene pairs that drive the observed drug compound enrichments in coexpression networks. Finally, CMap only contains drug-gene signatures from cultured human cancer cell lines. A comparison of drug compounds profiled in neuronal progenitor cells and differentiated neurons with 9 cancer cell lines profiled in CMap suggested that neuronal cell lines produce different connectivity patterns in a subset of compounds. ${ }^{52}$ Our pipeline would therefore benefit from the inclusion of drug-gene signatures derived from neuronal and glial (astrocytes, microglia, and oligodendrocytes) cell lines, as they become available.

In summary, we developed a novel drug repositioning approach that first identifies gene networks associated with Alzheimer disease before using the implicated networks as a molecular substrate for a drug repositioning analysis. Our approach identified drug mechanisms of action categories containing drug compounds with both proven and potential therapeutic benefit in Alzheimer disease. We identified the drug memantine, which is 1 of only 4 FDA-approved drugs for Alzheimer disease, supporting the validity of our approach. Follow-up molecular studies will seek to validate prioritized drug candidates in relevant human cell models, such as monocyte-induced microglia. Our approach will help researchers leverage genetic data for drug discovery and development in Alzheimer disease.

\section{Acknowledgment}

The authors thank the International Genomics of Alzheimer's Project (IGAP) for providing Alzheimer disease meta-analysis summary results data for these analyses. The investigators within IGAP contributed to the design and implementation of IGAP and/or provided data but did not participate in analysis or writing of this report. IGAP was made possible by the generous participation of the controls, the patients, and their families. E.R.G. is grateful to the President and Fellows of Clare Hall, University of Cambridge, for the stimulating intellectual environment during his fellowship in the college. E.R.G. is supported by the National Human Genome Research Institute of the National Institutes of Health under Award Numbers R35HG010718 and R01HG011138. The content is solely the responsibility of the authors and does not necessarily represent the official views of the National Institutes of Health.

\section{Study Funding}

No targeted funding reported.

\section{Disclosure}

Z.F. Gerring, A. White, and E.M. Derks received seed funding from the Takeda Pharmaceutical Company related to this project. The Takeda Pharmaceutical Company was not involved in study design or data analysis or in the writing and preparation of the manuscript. E.R. Gamazon reports no disclosures relevant to the manuscript. Go to Neurology.org/NG for full disclosures.

\section{Publication History}

Received by Neurology: Genetics January 31, 2021. Accepted in final form July 13, 2021. This manuscript was prepublished in doi.org/10.1101/ 853580 . 
Appendix Authors

\begin{tabular}{lll}
\hline Name & Location & Contribution \\
\hline $\begin{array}{l}\text { Zachary F. } \\
\text { Gerring, } \\
\text { PhD }\end{array}$ & $\begin{array}{l}\text { QIMR Berghofer Medical } \\
\text { Research Institute, Brisbane, } \\
\text { Queensland, Australia }\end{array}$ & $\begin{array}{l}\text { Designed and conceptualized } \\
\text { the study; analyzed the data; } \\
\text { interpreted the data; and } \\
\text { drafted the manuscript for } \\
\text { intellectual content }\end{array}$ \\
\hline $\begin{array}{l}\text { Eric R. } \\
\text { Gamazon, } \\
\text { PhD }\end{array}$ & $\begin{array}{l}\text { Venderbilt University } \\
\text { TN }\end{array}$ & $\begin{array}{l}\text { Interpreted the data and } \\
\text { revised the manuscript for } \\
\text { intellectual content }\end{array}$ \\
\hline $\begin{array}{l}\text { Anthony } \\
\text { White, } \\
\text { PhD }\end{array}$ & QIMR Berghofer Medical & $\begin{array}{l}\text { Interpreted the data and } \\
\text { revised the manuscript for } \\
\text { intellectual content }\end{array}$ \\
\hline $\begin{array}{l}\text { Eske M. } \\
\text { Derks, } \\
\text { PhD }\end{array}$ & Queensland, Australia & Research Institute, \\
Queensland, Australia & $\begin{array}{l}\text { Designed and conceptualized } \\
\text { the study and revised the } \\
\text { manuscript for intellectual } \\
\text { content }\end{array}$ \\
\hline
\end{tabular}

\section{References}

1. Zhang Q, Sidorenko J, Couvy-Duchesne B, et al. Risk prediction of late-onset Alzheimer's disease implies an oligogenic architecture. Nat Commun. 2020;11:4799.

2. Jansen IE, Savage JE, Watanabe K, et al. Genome-wide meta-analysis identifies new loci and functional pathways influencing Alzheimer's disease risk. Nat Genet. 2019; 51(3):404-413.

3. Gerring ZF, Lupton MK, Edey D, Gamazon ER, Derks EM. An analysis of genetically regulated gene expression across multiple tissues implicates novel gene candidates in Alzheimer's disease. Alzheimers Res Ther. 2020;12(1):43.

4. Di Paolo G, Kim T-W. Linking lipids to Alzheimer's disease: cholesterol and beyond. Nat Rev Neurosci. 2011;12(5):284-296.

5. Nelson MR, Tipney H, Painter JL, et al. The support of human genetic evidence for approved drug indications. Nat Genet. 2015;47(8):856-860.

6. Wang D, Liu S, Warrell J, et al. Comprehensive functional genomic resource and integrative model for the human brain. Science. 2018;362(6420):eaat8464.

7. Melé M, Ferreira PG, Reverter F, et al. The human transcriptome across tissues and individuals. Science. 2015;348(6235):660-665.

8. Mathys H, Davila-Velderrain J, Peng Z, et al. Single-cell transcriptomic analysis of Alzheimer's disease. Nature. 2019;570(7761):332-337.

9. Grubman A, Chew G, Ouyang JF, et al. A single cell brain atlas in human Alzheimer's disease. Biorxiv. 2019. doi: 10.1101/628347.

10. Langfelder P, Horvath S. WGCNA: an R package for weighted correlation network analysis. BMC Bioinformatics. 2008;9:559.

11. Gerring ZF, Gamazon ER, Derks EM. A gene co-expression network-based analysis of multiple brain tissues reveals novel genes and molecular pathways underlying major depression. PLoS Genet. 2019;15(7):e1008245.

12. Gamazon ER, Wheeler HE, Shah KP, et al. A gene-based association method for mapping traits using reference transcriptome data. Nat Genet. 2015;47(9):1091-1098.

13. Gusev A, Ko A, Shi H, et al. Integrative approaches for large-scale transcriptome-wide association studies. Nat Genet. 2016;48(3):245-252.

14. Zhang B, Gaiteri C, Bodea L-G, et al. Integrated systems approach identifies genetic nodes and networks in late-onset Alzheimer's disease. Cell. 2013;153(3):707-720.

15. Fang H, Beckmann G, Bountra C, et al. A genetics-led approach defines the drug target landscape of 30 immune-related traits. Nat Genet. 2019;51(7):1082-1091.

16. Lamb J, Crawford ED, Peck D, et al. The connectivity map: using gene-expression signatures to connect small molecules, genes, and disease. Science. 2006;313(5795): 1929-1935.

17. Langfelder P, Zhang B, Horvath S. Defining clusters from a hierarchical cluster tree: the Dynamic Tree Cut package for R. Bioinformatics. 2008;24(5):719-720.

18. Morabito S, Miyoshi E, Michael N, Swarup V. Integrative genomics approach identifies conserved transcriptomic networks in Alzheimer's disease. Hum Mol Genet. 2020;29(17):2899-2919.

19. de Leeuw CA, Mooij JM, Heskes T, Posthuma D. MAGMA: generalized gene-set analysis of GWAS data. PLoS Comput Biol Public Libr Sci. 2015;11(4):e1004219.

20. Reimand J, Arak T, Adler P, et al g:Profiler - a web server for functional interpretation of gene lists (2016 update). Nucleic Acids Res. 2016;44(W1):W83-W89.

21. Langfelder P, Luo R, Oldham MC, Horvath S. Is my network module preserved and reproducible? PLoS Comput Biol. 2011;7(1):e1001057.

22. Delaneau O, Marchini J; 1000 Genomes Project Consortium. Integrating sequence and array data to create an improved 1000 Genomes Project haplotype reference panel. Nat Commun. 2014;5:3934.
23. Wishart DS, Feunang YD, Guo AC, et al. DrugBank 5.0: a major update to the DrugBank database for 2018. Nucleic Acids Res. 2017;46(D1):D1074-D1082.

24. Cotto KC, Wagner AH, Feng Y-Y, et al. DGIdb 3.0: a redesign and expansion of the drug-gene interaction database. Nucleic Acids Res. 2017;46(D1):D1068-D1073.

25. Pardiñas AF, Holmans P, Pocklington AJ, et al. Common schizophrenia alleles are enriched in mutation-intolerant genes and in regions under strong background selection. Nat Genet. 2018;50(3):381-389.

26. Siminoff LA, Wilson-Genderson M, Gardiner HM, Mosavel M, Barker KL. Consent to a postmortem tissue procurement study: distinguishing family decision makers' knowledge of the genotype-tissue expression project. Biopreserv Biobank. 2018;16(3):200-206.

27. Tible OP, Riese F, Savaskan E, von Gunten A. Best practice in the management of behavioural and psychological symptoms of dementia. Ther Adv Neurol Disord. 2017, 10(8):297-309.

28. Minter MR, Taylor JM, Crack PJ. The contribution of neuroinflammation to amyloid toxicity in Alzheimer's disease. J Neurochem. 2016;136(3):457-474.

29. Chou RC, Kane M, Ghimire S, Gautam S, Gui J. Treatment for rheumatoid arthritis and risk of Alzheimer's disease: a nested case-control analysis. CNS Drugs. 2016, 30(11):1111-1120

30. Allen M, Carrasquillo MM, Funk C, et al. Human whole genome genotype and transcriptome data for Alzheimer's and other neurodegenerative diseases. Sci Data. 2016;3:160089.

31. Mostafavi S, Gaiteri C, Sullivan SE, et al. A molecular network of the aging human brain provides insights into the pathology and cognitive decline of Alzheimer's disease. Nat Neurosci. 2018;21(6):811-819.

32. Wang M, Beckmann ND, Roussos P, et al. The Mount Sinai cohort of large-scale genomic, transcriptomic and proteomic data in Alzheimer's disease. Sci Data. 2018;5:180185.

33. Plenge RM. Priority index for human genetics and drug discovery. Nat Genet. 2019; 51(7):1073-1075.

34. Wang R, Reddy H. Role of glutamate and NMDA in Alzheimer's disease. J Alzheimers Desese. 2017;57(4):1041-1048.

35. Heneka MT, Carson MJ, Khoury J El, et al. Neuroinflammation in Alzheimer's disease. Lancet Neurol. 2015;14(4):388-405.

36. Kunkle BW, Grenier-Boley B, Sims R, et al. Genetic meta-analysis of diagnosed Alzheimer's disease identifies new risk loci and implicates $A \beta$, tau, immunity and lipid processing. Nat Genet. 2019;51(3):414-430.

37. Spangenberg E, Severson PL, Hohsfield LA, et al. Sustained microglial depletion with CSF1R inhibitor impairs parenchymal plaque development in an Alzheimer's disease model. Nat Commun. 2019;10(1):3758

38. Ulland TK, Colonna M. TREM2 - a key player in microglial biology and Alzheimer disease. Nat Rev Neurol. 2018;14(11):667-675.

39. Cummings JL, Lyketsos CG, Peskind ER, et al. Effect of dextromethorphan-quinidine on agitation in patients with Alzheimer disease dementia: a randomized clinical trial. JAMA. 2015;314(12):1242-1254.

40. Matt SM, Gaskill PJ. Where is dopamine and how do immune cells see it?: dopaminemediated immune cell function in Health and disease. I Neuroimmune Pharmacol. 2020;15(1):114-164.

41. Reisberg B, Doody R, Stöffler A, Schmitt F, Ferris S, Möbius HJ. Memantine in moderate-to-severe Alzheimer's disease. N Engl J Med. 2003;348(14):1333-1341.

42. Costa RO, Lacor PN, Ferreira IL, et al. Endoplasmic reticulum stress occurs downstream of GluN2B subunit of N-methyl-d-aspartate receptor in mature hippocampal cultures treated with amyloid- $\beta$ oligomers. Aging Cell. 2012;11(5):823-833.

43. Klawe C, Maschke M. Flupirtine: pharmacology and clinical applications of a nonopioid analgesic and potentially neuroprotective compound. Expert Opin Pharmacother. 2009;10(9):1495-1500

44. García-Laínez G, Sancho M, García-Bayarri V, Orzáez M. Identification and validation of uterine stimulant methylergometrine as a potential inhibitor of caspase- 1 activation. Apoptosis. 2017;22(10):1310-1318.

45. Finan C, Gaulton A, Kruger FA, et al. The druggable genome and support for target identification and validation in drug development. Sci Transl Med. 2017;9(383) eaag1166.

46. So H-C, Chau CK-L, Chiu W-T, et al. Analysis of genome-wide association data highlights candidates for drug repositioning in psychiatry. Nat Neurosci. 2017;20(10): 1342-1349.

47. Aisen PS, Schafer KA, Grundman M, et al. Effects of rofecoxib or naproxen vs placebo on Alzheimer disease progression: a randomized controlled trial. JAMA. 2003; 289(21):2819-2826.

48. Lyketsos CG, Breitner JCS, Green RC, et al. Naproxen and celecoxib do not prevent $\mathrm{AD}$ in early results from a randomized controlled trial. Neurology 2007;68(21): 1800-1808.

49. Kinney JW, Bemiller SM, Murtishaw AS, Leisgang AM, Salazar AM, Lamb BT. Inflammation as a central mechanism in Alzheimer's disease. Alzheimers Dement (New York, N Y). 2018;4:575-590.

50. Pimenova AA, Raj T, Goate AM. Untangling genetic risk for Alzheimer's disease. Biol Psychiatry. 2018;83(4):300-310.

51. Efthymiou AG, Goate AM. Late onset Alzheimer's disease genetics implicates microglial pathways in disease risk. Mol Neurodegener Biomed Cent. 2017;12(1):43.

52. Subramanian A, Narayan R, Corsello SM, et al. A next generation connectivity map: L1000 platform and the first 1,000,000 profiles. Cell. 2017;171(6):1437-1452.e17. 


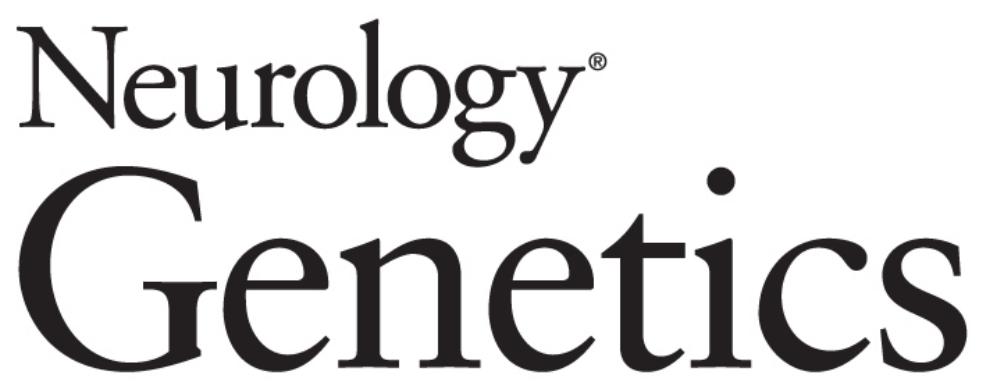
Integrative Network-Based Analysis Reveals Gene Networks and Novel Drug Repositioning Candidates for Alzheimer Disease
Zachary F. Gerring, Eric R. Gamazon, Anthony White, et al. Neurol Genet 2021;7;
DOI 10.1212/NXG.0000000000000622

This information is current as of September 13, 2021

Neurol Genet is an official journal of the American Academy of Neurology. Published since April 2015, it is an open-access, online-only, continuous publication journal. Copyright Copyright ( 2021 The Author(s). Published by Wolters Kluwer Health, Inc. on behalf of the American Academy of Neurology.. All rights reserved. Online ISSN: 2376-7839.

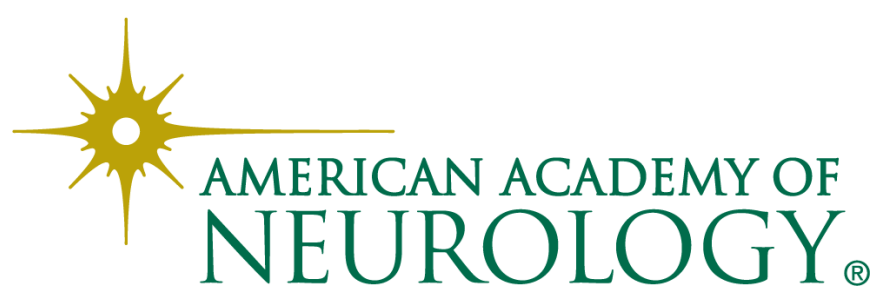




\section{Updated Information \& Services}

References

Citations

Subspecialty Collections

Permissions \& Licensing

Reprints including high resolution figures, can be found at: http://ng.neurology.org/content/7/5/e622.full.html

This article cites 52 articles, 5 of which you can access for free at: http://ng.neurology.org/content/7/5/e622.full.html\#\#ref-list-1

This article has been cited by 3 HighWire-hosted articles: http://ng.neurology.org/content/7/5/e622.full.html\#\#otherarticles

This article, along with others on similar topics, appears in the following collection(s):

Alzheimer's disease

http://ng.neurology.org//cgi/collection/alzheimers_disease Association studies in genetics

http://ng.neurology.org//cgi/collection/association_studies_in_genetics Gene expression studies

http://ng.neurology.org//cgi/collection/gene_expression_studies

Information about reproducing this article in parts (figures,tables) or in its entirety can be found online at:

http://ng.neurology.org/misc/about.xhtml\#permissions

Information about ordering reprints can be found online:

http://ng.neurology.org/misc/addir.xhtml\#reprintsus

Neurol Genet is an official journal of the American Academy of Neurology. Published since April 2015, it is an open-access, online-only, continuous publication journal. Copyright Copyright $\odot 2021$ The Author(s). Published by Wolters Kluwer Health, Inc. on behalf of the American Academy of Neurology.. All rights reserved. Online ISSN: 2376-7839.

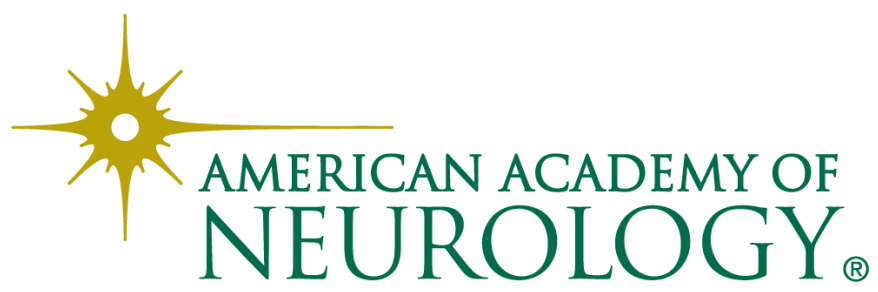

